\title{
Correction to: Recovery trajectories in common musculoskeletal complaints by diagnosis contra prognostic phenotypes
}

Lene Aasdahl1 ${ }^{1,2^{*}}$, Fredrik Granviken ${ }^{1,3}$, Ingebrigt Meisingset ${ }^{1}$, Astrid Woodhouse ${ }^{1}$, Kari Anne I. Evensen ${ }^{4,5,6}$ and Ottar Vasseljen ${ }^{1}$

\section{Correction to: BMC Musculoskelet Disord 22, 455 (2021)} https://doi.org/10.1186/s12891-021-04332-3

Following the publication of the original article [1] the authors noticed that the Online Tables 1 and 2 (supplementary) were missing in the proof. The citations 22:455 https://doi.org/10.1186/s12891-021-04332-3. were linked to the normal tables.

The original article [1] has been updated.

\section{Supplementary Information}

The online version contains supplementary material available at https://doi. org/10.1186/s12891-021-04428-w.

Additional file 1: Online Table 1. Estimated mean change in Patient specific functional scale (PSFS) from baseline. Online Table 2. Estimated mean change in pain from baseline.

\section{Author details}

'Department of Public Health and Nursing, Norwegian University of Science and Technology (NTNU), Postboks 8905, MTFS, 7491 Trondheim, Norway. ${ }^{2}$ Unicare Helsefort Rehabilitation Centre, Rissa, Norway. ${ }^{3}$ Department of Physical Medicine and Rehabilitation, St.Olavs Hospital, Trondheim, Norway. ${ }^{4}$ Department of Clinical and Molecular Medicine, NTNU, Trondheim, Norway. ${ }^{5}$ Department of Physiotherapy, Oslo Metropolitan University, Oslo, Norway.

${ }^{6}$ Unit for Physiotherapy Services, Trondheim Municipality, Trondheim, Norway.

Published online: 25 June 2021

\section{Reference}

1. Aasdahl L, Granviken F, Meisingset I, Woodhouse A, Evensen KAl, Vasseljen

O. Recovery trajectories in common musculoskeletal complaints by

The original article can be found online at https://doi.org/10.1186/s12891021-04332-3.

* Correspondence: lene.aasdahl@ntnu.no

'Department of Public Health and Nursing, Norwegian University of Science and Technology (NTNU), Postboks 8905, MTFS, 7491 Trondheim, Norway

${ }^{2}$ Unicare Helsefort Rehabilitation Centre, Rissa, Norway

Full list of author information is available at the end of the article

C C The Author(s). 2021 Open Access This article is licensed under a Creative Commons Attribution 4.0 International License, which permits use, sharing, adaptation, distribution and reproduction in any medium or format, as long as you give appropriate credit to the original author(s) and the source, provide a link to the Creative Commons licence, and indicate if changes were made. The images or other third party material in this article are included in the article's Creative Commons licence, unless indicated otherwise in a credit line to the material. If material is not included in the article's Creative Commons licence and your intended use is not permitted by statutory regulation or exceeds the permitted use, you will need to obtain permission directly from the copyright holder. To view a copy of this licence, visit http://creativecommons.org/licenses/by/4.0/. The Creative Commons Public Domain Dedication waiver (http://creativecommons.org/publicdomain/zero/1.0/) applies to the data made available in this article, unless otherwise stated in a credit line to the data. 